\title{
Diagnostic accuracy of procalcitonin for overall and complicated acute appendicitis in children: a meta-analysis
}

\author{
Wei Cui ${ }^{1,2}$, Haipeng Liu ${ }^{1,2^{*}}$ (D) Hong Ni ${ }^{1,2}$, Xianhui Qin ${ }^{3}$ and Liran Zhu ${ }^{1,2}$
}

\begin{abstract}
Background: Diagnostic value of procalcitonin (PCT) for acute appendicitis (AA) has been evaluated in adult patients, but the application in children remains controversial. The aim of this study was to evaluate the diagnostic value of PCT for overall and complicated AA in children.

Methods: The PubMed, EMBASE, Web of Science, Cochrane Database of Systematic Reviews, Chinese National Knowledge Infrastructure, and Wanfang were searched along with reference lists of relevant articles up to January 2018 without language restrictions. Original articles that reported the performance of PCT in the diagnosis of pediatric AA and associated complications were selected. To assess the diagnostic value of PCT, sensitivity, specificity, diagnostic odds ratios (DORs), summary receiver operating characteristic (ROC) curves, area under the curve (AUC), and 95\% confidence intervals (95\% Cls) were estimated.
\end{abstract}

Results: Seven qualifying studies (504 confirmed AA and 368 controls) from 6 countries for overall AA and 4 studies (187 complicated AA and 185 uncomplicated AA) for complicated AA from 3 countries were identified. The pooled sensitivity and specificity of PCT for the diagnosis of pediatric AA were 0.62 (95\% Cl: $0.57-0.66)$ and 0.86 (95\% Cl: 0.82-0.89), respectively. The DOR was 21.4 (95\% Cl: 3.64-126.1) and the AUC was 0.955. PCT was more accurate in diagnosing complicated appendicitis, with a pooled sensitivity of 0.89 ( $95 \% \mathrm{Cl}: 0.84-0.93)$, specificity of 0.90 (95\% Cl: 0.86-0.94), and DOR of 76.73 (95\% Cl: 21.6-272.9).

Conclusion: This meta-analysis showed that PCT may have potential value in diagnosing pediatric AA. Moreover, PCT had greater diagnostic value in identifying pediatric complicated appendicitis.

Keywords: Acute appendicitis, Diagnosis, Meta-analysis, Pediatric, Procalcitonin

\section{Background}

Acute appendicitis| (AA) is the most frequent abdominal surgical emergency in children [1]. Although the mortality rate of pediatric AA has declined in recent years, delay in diagnosis and treatment for AA result in an increased perforation rate, post-operative morbidity, mortality, and hospital length of stay [2]. Approximately $16.5 \%$ of appendicitis progresses to complicated appendicitis, such as perforation, gangrene, peritonitis, or abscess formation, which may lead to higher costs and even death $[3,4]$. Moreover, patients with complicated

\footnotetext{
* Correspondence: itishaipeng@yeah.net

'Department of Scientific Research and Education, Anhui Provincial

Children's Hospital, Wangjiang Road, Hefei 230051, Anhui, China

${ }^{2}$ Anhui Institute of Pediatric Research, Hefei, Anhui, China

Full list of author information is available at the end of the article
}

AA are more likely to have post-surgical complications (abscesses, intestinal obstruction, and hemodynamic instability) [5] than patients with uncomplicated AA. It is crucial to identify AA early and to discriminate uncomplicated and complicated AA so that preemptive therapy can be performed.

Non-specific signs (irritability, anorexia, and lethargy) in patients with appendicitis are difficult for parents and pediatricians to interpret, thus leading to a high misdiagnosis rate. Overall, the misdiagnosis rates of AA are 70 $100 \%$ in children $<3$ years of age, $19-57 \%$ in preschool children, $12-28 \%$ in school-aged children, and up to $15 \%$ in adolescents [6]. In-hospital observation and repeated clinical examinations during evaluation of a patient with AA may easily lead to an increase in false-

(c) The Author(s). 2019 Open Access This article is distributed under the terms of the Creative Commons Attribution 4.0 International License (http://creativecommons.org/licenses/by/4.0/), which permits unrestricted use, distribution, and 
positive diagnoses and operations [2]. The use of ultrasound, computerized tomography (CT), and magnetic resonance image (MRI) could potentially improve the accuracy of AA; however, use remains limited due to radiation exposure risk, lifetime risk of cancer, the increase in cost, and lack of universal availability [7, 8]. Recently, biomarkers, such as procalcitonin (PCT), have been shown to have potentially good diagnostic accuracy and reliability, which may be more appropriate indices in the diagnosis of appendicitis, and in some cases predict the severity of the condition.

PCT is the prohormone of calcitonin. PCT levels rise rapidly after systemic bacterial infection but remain low in viral infections and inflammatory diseases. The role of PCT in the diagnosis of pediatric AA is still inconclusive. The aim of the current meta-analysis was to evaluate the diagnostic value of PCT for overall and complicated AA in children.

\section{Material and methods}

\section{Search strategy and selection criteria}

We searched PubMed, EMBASE, CNKI, and Wanfang from inception to April 2018 with MeSH terms ("procalcitonin OR procalcitonin OR PCT" and "appendicitis OR ecphyaditis OR epityphlitis OR acute appendicitis or chronic appendicitis" and "pediatric OR paediatric OR child OR children"). Additionally, manual searches were performed of bibliographies for all relevant trials and review articles. The searches were restricted to human studies and clinical trials. There were no language restrictions. A team of experts in the relevant field was assembled.

A standard protocol for study selection and data abstraction was developed by our multidisciplinary team. Studies that met the following criteria were included: (1) evaluation of PCT to diagnose pediatric AA and associated complications; and (2) sufficient data to construct a $2 \times 2$ contingency table. The exclusion criteria included: (1) a lack of PCT diagnostic accuracy; (2) insufficient data to reconstruct $2 \times 2$ tables; and (3) case reports, review articles, editorials, and clinical guidelines.

\section{Data extraction}

All data from eligible studies were independently abstracted in duplicate by two investigators according to standard protocol and reviewed by a third investigator. Discrepancies were resolved through discussion with the multidisciplinary research team that developed the protocol. The following data were extracted: first author's name; year of publication; study population characteristics; number of patients and controls included; methods for PCT measurement; cut-off values; and results of TP, true positive; FP, false positive; TN, true negative; FN, false negative.

\section{Quality assessment}

The quality of the selected studies was assessed by means of the Quality Assessment of Diagnostic Accuracy Studies (QUADAS)-2 criteria [9], which consists of the following four domains: patient selection; index test; reference standard; and flow and timing. The inconsistency index $\left(I^{2}\right)$ was calculated to quantify the extent of heterogeneity. In this analysis, the pathologic examination of the surgical specimen was used as the reference standard to verify AA for patients undergoing surgery. We have reported according to Preferred Reporting Items for Systematic Reviews and Meta-Analyses-2 (PRISMA-2) and Assessing the Methodological Quality of Systematic Reviews (AMSTAR) guidelines.

\section{Statistical analysis}

The pooled sensitivity, specificity, positive likelihood ratio (PLR), negative likelihood ratio (NLR), and diagnostic odds ratios (DORs) of PCT were calculated for each included study. A summary ROC curve was created by plotting the true-positive rate (sensitivity) against the false-positive rate $(1-$ specificity) at various cut-off values from individual studies using random-effect models. The threshold effect was investigated using the Spearman correlation coefficient. Statistical analyses were performed using Meta-Disc 1.4 for Windows and Review manager 5.3. All statistical tests were two-sided with statistical significance set at $P<0.050$.

\section{Results}

Twenty-five potentially relevant papers were retrieved using the systematic search. Our initial literature search identified 15 studies for detailed assessment. Of these studies, four were excluded due to a lack of data on the diagnostic tests of interest and two did not have sufficient data to reconstruct $2 \times 2$ tables (Fig. 1). Our final analysis included nine studies [5, 10-17]. The identified studies, published between 2005 and 2017, were conducted in 6 countries (India, Greece, France, Spain, China, and Turkey) with sample sizes ranging from 50 to 212 participants. Seven studies [10, 11, 13-17] reported the use of PCT in the diagnosis of overall appendicitis and four studies $[5,12,15,16]$ provided the predictive value of PCT for complicated AA in pediatric patients. Tables 1 and 2 summarize the characteristics of the included studies that used PCT to assess overall and complicated appendicitis.

Quality assessment was based on the QUADAS-2 guidelines for all nine studies, as shown in Fig. 2. Four studies had an 'unclear' or 'high' risk of bias concerning patient selection due to inconsistent inclusion criteria. Only two studies had an 'unclear' 


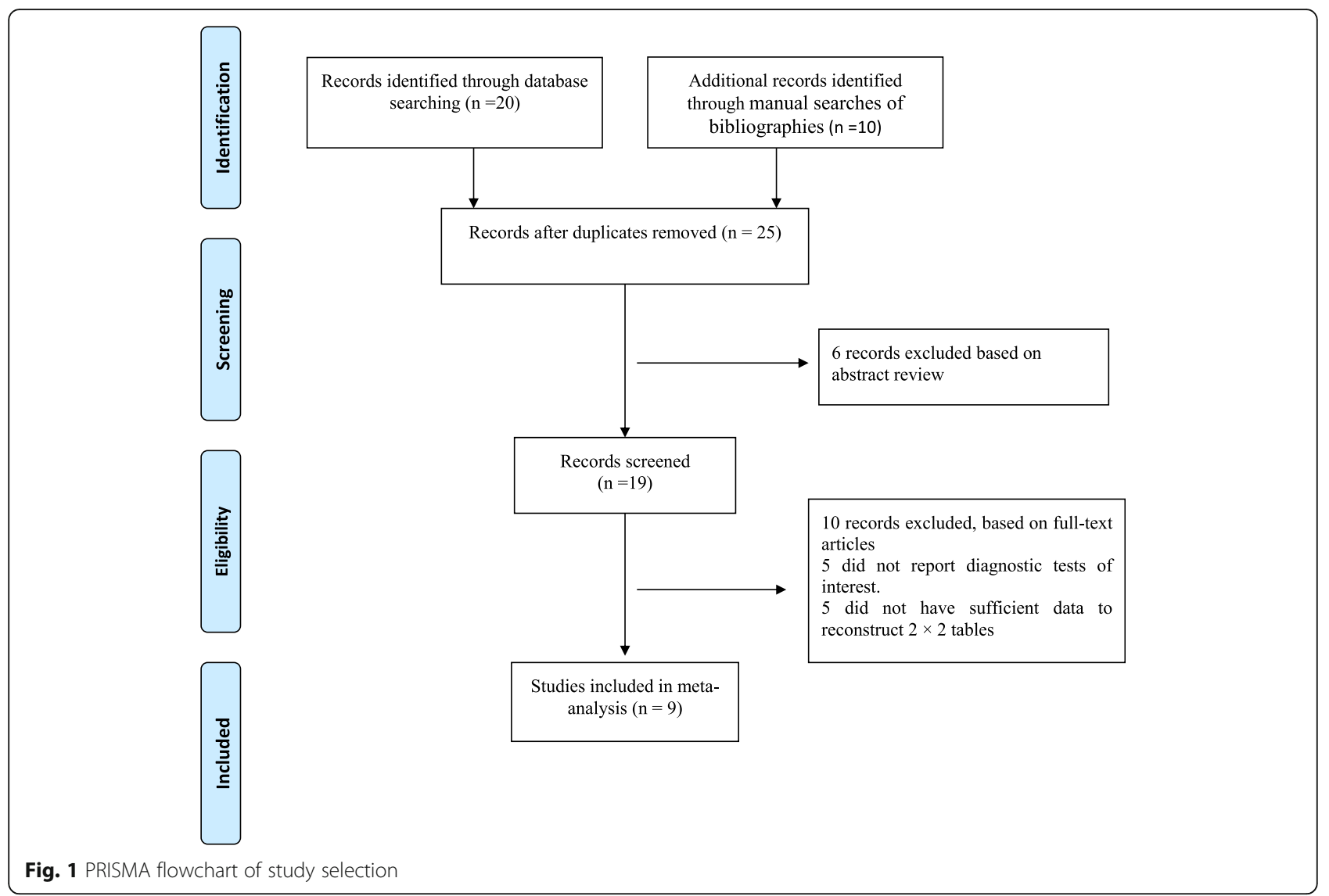

or 'high' risk of bias with respect to the index test and reference standards due to the same reference standard (histologic examination) and the near-same thresholds in which the studies were assessed. Three studies had an 'unclear' or 'high' risk of bias with respect to patient flow.

\section{Diagnostic accuracy analyses}

The Spearman correction coefficient between PCT and pediatric AA was calculated to be $0.5(P=0.253)$, indicating that there is no heterogeneity from threshold effects. The pooled DOR for overall and complicated AA was 21.4 (95\% confidence interval (CI): 3.64-126.1) and 76.7 (95\% CI: 21.57-272.9), respectively. The AUC for the summary ROC of the PCT test for diagnosis of overall AA was 0.955 followed by 0.956 for complicated AA, indicating a higher predictive value for complicated AA in children, as shown in Figs. 3 and 4.

\section{Overall diagnostic indices}

The pooled sensitivity and specificity for PCT are shown in Table 3. Overall, the meta-analysis showed a pooled sensitivity of PCT for the diagnosis of overall AA of 0.62 (95\% CI: $\left.0.57-0.66 ; I^{2}=96.3 \%\right)$ and specificity of 0.86

Table 1 Characteristics of the included studies that used PCT to assess pediatric acute appendicitis in the meta-analysis

\begin{tabular}{|c|c|c|c|c|c|c|c|c|c|c|c|c|c|}
\hline First author & $\begin{array}{l}\text { Year of } \\
\text { publication }\end{array}$ & Country & $A A$ & Control & $\begin{array}{l}\text { Age, years; } \\
\text { Mean (range) }\end{array}$ & $\begin{array}{l}\text { PCT testing } \\
\text { system }\end{array}$ & $\begin{array}{l}\text { Cut-off } \\
\text { (ng/ml) }\end{array}$ & $\begin{array}{l}\text { Sensitivity } \\
(\%)\end{array}$ & $\begin{array}{l}\text { Specificity } \\
(\%)\end{array}$ & $\begin{array}{l}\text { No. of } \\
\text { TP }\end{array}$ & $\begin{array}{l}\text { No. of } \\
\text { FP }\end{array}$ & $\begin{array}{l}\text { No. of } \\
\text { FN }\end{array}$ & $\begin{array}{l}\text { No. of } \\
\text { TN }\end{array}$ \\
\hline Alkan [10] & 2017 & Turkey & 56 & 40 & $9(7-11)$ & LUMI test & 0.37 & 32.3 & 89.7 & 18 & 4 & 38 & 36 \\
\hline Benito [17] & 2016 & Spain & 89 & 96 & $9.32 \pm 2.7$ & LUMI test & 0.1 & 38.1 & 64.5 & 34 & 34 & 55 & 62 \\
\hline Wang [11] & 2016 & China & 96 & 56 & $7.4 \pm 2.1$ & LUMI test & 0.5 & 85.4 & 90.6 & 82 & 5 & 14 & 51 \\
\hline Li [13] & 2015 & China & 42 & 36 & $12(5-17)$ & LUMI test & 0.5 & 95.2 & 88.9 & 40 & 4 & 2 & 32 \\
\hline Chandel [16] & 2011 & India & 23 & 27 & $3-15$ & LUMI test & 0.5 & $95 \cdot 6$ & 100 & 22 & 0 & 1 & 17 \\
\hline Kafetzis [15] & 2005 & Greece & 130 & 82 & $9 \pm 2.2$ & LUMI test & 0.5 & $73 \cdot 0$ & $95 \cdot 0$ & 47 & 8 & 7 & 140 \\
\hline Kouame [14] & 2005 & France & 68 & 31 & $2-15$ & LUMI test & 0.5 & $28 \cdot 0$ & 100 & 19 & 4 & 49 & 29 \\
\hline
\end{tabular}

Abbreviations: $P C T$ procalcitonin, $A A$ acute appendicitis, $T P$ true positive, $F P$ false positive, $T N$ true negative, $F N$ false negative, $L U M I t e s t$ immunoluminometric method 
Table 2 Characteristics of the four included studies that used PCT to assess pediatric complicated appendicitis

\begin{tabular}{|c|c|c|c|c|c|c|c|c|c|c|c|c|}
\hline First Author & $\begin{array}{l}\text { Year of } \\
\text { Publication }\end{array}$ & Country & AA & CA & $\begin{array}{l}\text { Age, years: } \\
\text { Mean (range) }\end{array}$ & $\begin{array}{l}\text { Cut-off } \\
(\mathrm{ng} / \mathrm{ml})\end{array}$ & $\begin{array}{l}\text { Sensitivity } \\
(\%)\end{array}$ & $\begin{array}{l}\text { Specificity } \\
(\%)\end{array}$ & $\begin{array}{l}\text { No. of } \\
\text { TP }\end{array}$ & $\begin{array}{l}\text { No. of } \\
\text { FP }\end{array}$ & $\begin{array}{l}\text { No. of } \\
\text { FN }\end{array}$ & $\begin{array}{l}\text { No. of } \\
\text { TN }\end{array}$ \\
\hline Yuchi [12] & 2015 & China & 38 & 70 & $15.2 \pm 2.1$ & 0.5 & 81 & 82 & 57 & 7 & 13 & 31 \\
\hline Teresa [5] & 2012 & Spain & 69 & 42 & $1.2-17.1$ & 0.18 & 97 & 80 & 67 & 8 & 2 & 34 \\
\hline $\begin{array}{l}\text { Chandel } \\
{[16]}\end{array}$ & 2011 & India & 12 & 11 & $3-15$ & 0.74 & 100 & 100 & 11 & 0 & 0 & 12 \\
\hline Kafetzis [15] & 2005 & Greece & 66 & 64 & $9 \pm 2.2$ & 0.5 & 73.0 & 95.0 & 47 & 2 & 17 & 64 \\
\hline
\end{tabular}

Abbreviations: $P C T$ procalcitonin, $A A$ acute appendicitis, $C A$ complicated appendicitis, $T P$ true positive, $F P$ false positive, $T N$ true negative, $F N$ false negative

(95\% CI: $\left.0.82-0.89 ; I^{2}=86.7 \%\right)$. The combined PLR was 5.33 (95\% CI: $1.79-15.8$ ) with respect to the combined NLR of 0.29 (95\% CI: $0.15-0.58$ ). The pooled sensitivity and specificity of PCT for the diagnosis of complicated AA were 0.89 (95\% CI: $0.84-0.93 ; I^{2}=76.1 \%$ ) and 0.90 (95\% CI: $0.86-0.94 ; I^{2}=75.3 \%$ ), respectively. The combined PLR was 7.68 (95\% CI: 3.66-16.14) with respect to the combined NLR of 0.12 (95\% CI: 0.05-0.27).

\section{Subgroup analysis of source populations}

The results of subgroup analysis are summarized in Table 3. Analysis of three studies from Asian populations had a superior diagnostic accuracy for PCT with pooled sensitivity of 0.90 (95\% CI: $\left.0.84-0.94, I^{2}=61.6 \%\right)$, specificity of 0.91 (95\% CI: $0.84-0.96 ; I^{2}=17.8 \%$ ), and an AUC of 0.963 compared with the overall pooled estimates (sensitivity of 0.62 (95\% CI: 0.57-0.66) and specificity of 0.86 (95\% CI: 0.82-0.89)). The corresponding values for the source populations from non- Asian populations were 0.44 (95\% CI: $0.38-0.50$ ) for sensitivity, 0.84 (95\% CI: $0.80-0.88$ ) for specificity, and 0.90 for the AUC (Table 3).

\section{Discussions}

PCT is the prohormone of calcitonin, with normal plasma reference levels of $0.1-0.5 \mathrm{ng} / \mathrm{ml}$ in healthy individuals. The PCT level increases rapidly after a systemic bacterial infection, but with no significant increase in viral infections, making PCT one of the most important early laboratory signs for systemic bacterial and fungal infections [18-20]. Several studies have shown PCT to be an excellent marker of bacterial infections and the PCT level increases rapidly with the severity of infection in children [21, 22]. As appendicitis is difficult to be diagnosed in a timely fashion, which delays surgical intervention, it is meaningful to evaluate the value of PCT in diagnosing $\mathrm{AA}$ and complicated $\mathrm{AA}$, as in the present analysis.

Our study comprehensively evaluated the diagnostic value of PCT in pediatric patients with AA with a sensitivity of 0.62 (95\% CI: $0.57-0.66)$ and a specificity of 0.86 (95\% CI: 0.82-0.89), which indicated the potential value in diagnosing pediatric AA. Also, the mean value of PCT was significantly higher in the appendicitis group in these studies under review. Of note, a higher sensitivity and specificity were observed in pediatric patients with complicated AA (sensitivity, 0.89 (95\% CI: 0.840.93) and specificity, 0.90 (95\% CI: 0.86-0.94)) than the overall AA. Hence, our study suggests a better diagnostic accuracy for PCT in complicated AA than overall AA.

Previous research findings on the diagnostic value of PCT in AA and complicated AA have been inconsistent $[2,23,24]$. Yu et al. [23] showed a low value of PCT in diagnosing AA with a pooled sensitivity of 0.33 and a specificity of 0.89 in patients with all ages, including adults and children; however, Wu et al. [24] observed a useful application with complicated appendicitis than in overall AA in adults. Moreover, a study by Muhammad

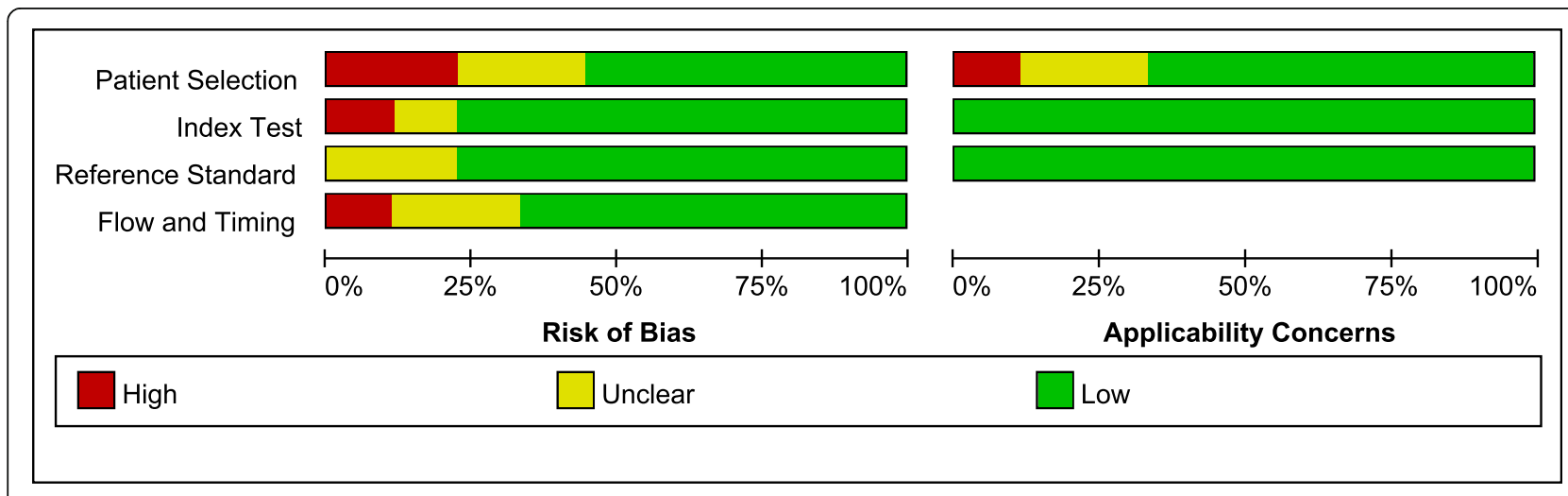

Fig. 2 Graph displaying the percentage of studies with varying degree of bias and varying applicability for each of the four QUADAS-2 domains 


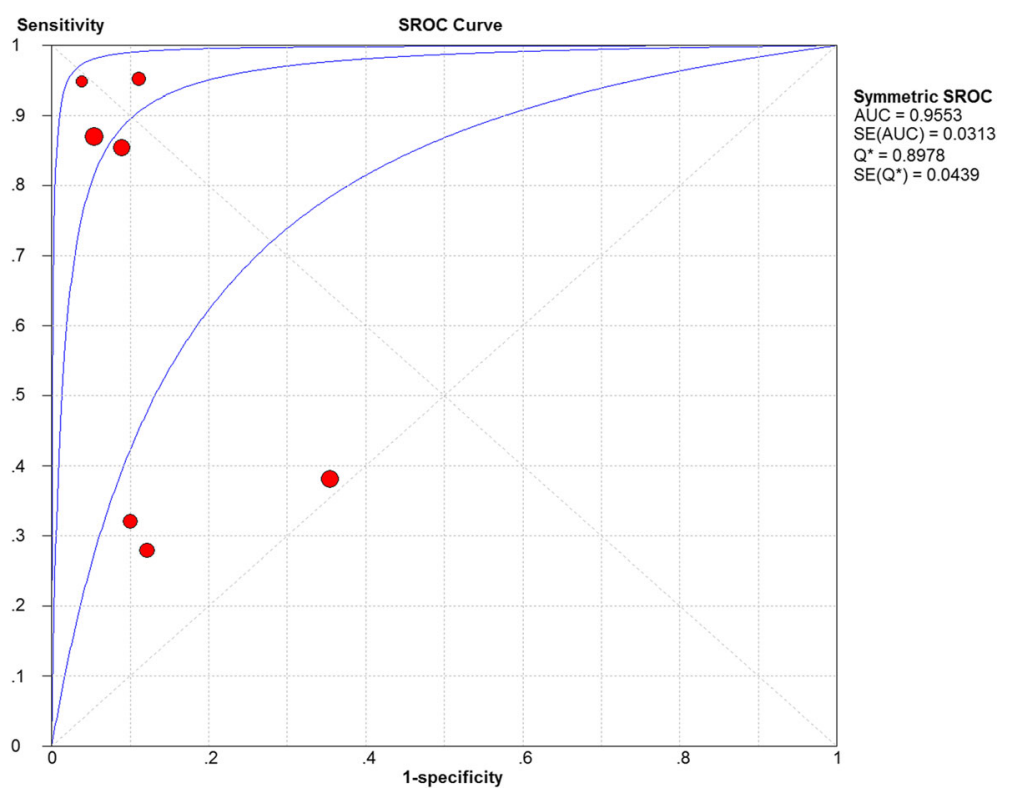

Fig. 3 Receiver operating characteristic (ROC) curve analysis for the diagnosis of children with acute appendicitis using a procalcitonin, $A \cup C=$ area $u n d e r$ the curve, $S R O C=$ summary receiver operating characteristic

et al. [25] found that PCT were applicable in diagnosing AA with sensitivity and specificity of 0.85 and 0.74 in an adult population, which outperformed serum CRP. The possible reasons for these contradictory findings include differences in study methodology, sample size, and population. Our subgroup analysis also suggested high levels of sensitivity and specificity in Asian children (India and China), which indicated possible population- based diagnostic effects; however, the exact mechanisms regarding the diagnostic value of $\mathrm{PCT}$ to $\mathrm{AA}$ in each population warrants further investigation, and our findings should also be confirmed.

The diagnostic value of other biomarkers, such as the C-reactive protein (CRP), white blood cell (WBC) count, bilirubin, and interleukin 6 (IL-6) levels for AA have been evaluated in literatures [26-33]. For example,

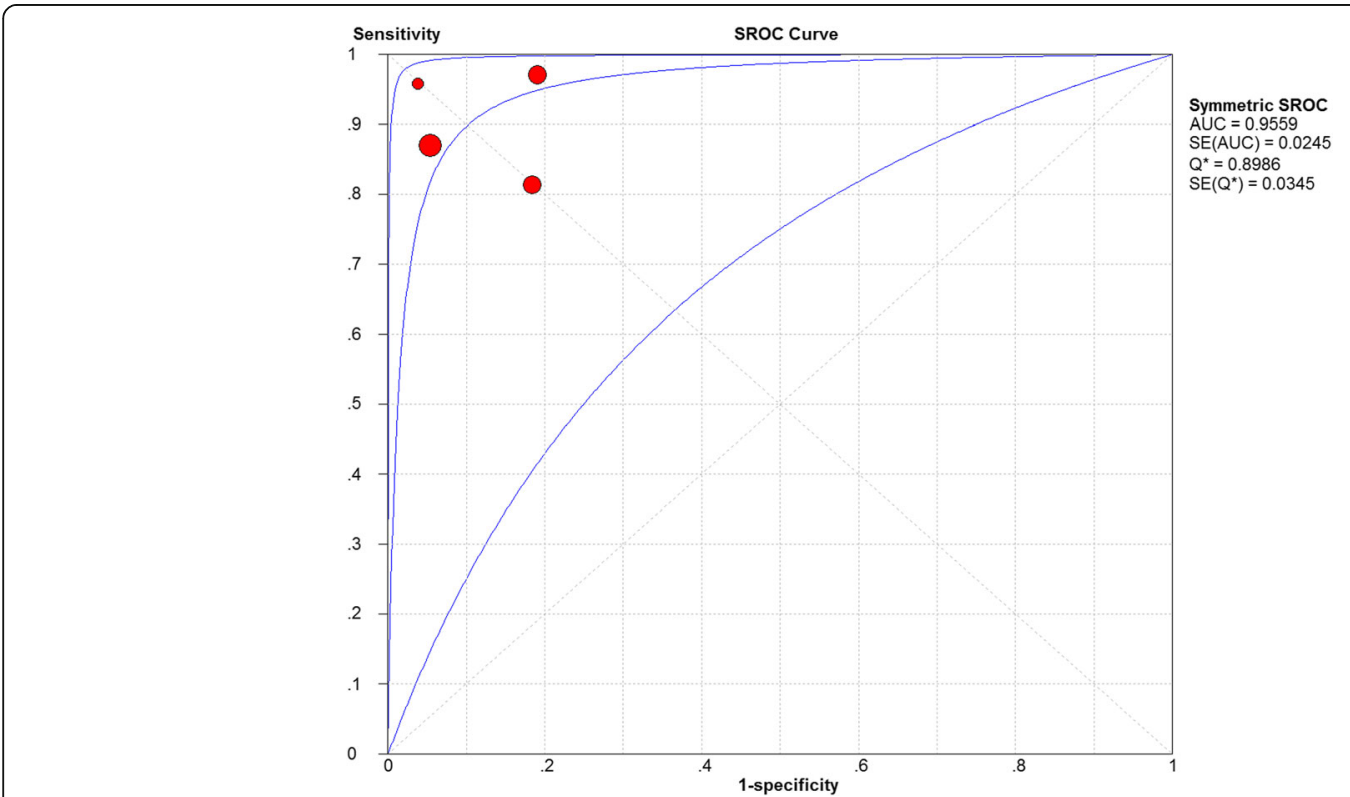

Fig. 4 Receiver operating characteristic (ROC) curve analysis for the prediction of children with complicated appendicitis using a procalcitonin, $\mathrm{AUC}=$ area under the curve, $\mathrm{SROC}=$ summary receiver operating characteristic 
Table 3 Summary of diagnostic accuracy parameters for meta-analysis

\begin{tabular}{|c|c|c|c|c|c|c|c|}
\hline & $\begin{array}{l}\text { No. of } \\
\text { studies }\end{array}$ & $\begin{array}{l}\text { Sensitivity } \\
(\%)\end{array}$ & $\begin{array}{l}\text { Specificity } \\
(\%)\end{array}$ & $\begin{array}{l}\text { Positive likelihood } \\
\text { ratio }\end{array}$ & $\begin{array}{l}\text { Negative likelihood } \\
\text { ratio }\end{array}$ & Diagnostic OR & $\begin{array}{l}\text { Area under } \\
\text { ROC curve }\end{array}$ \\
\hline PCT for AA & 7 & $62(57,66)$ & $86(82,89)$ & $5.33(1.79,15.84)$ & $0.29(0.15,0.58)$ & $21.4(3.64,126.1)$ & 0.955 \\
\hline PCT for CA & 4 & $89(84,93)$ & $90(86,94)$ & $7.68(3.66,16.14)$ & $0.12(0.05,0.27)$ & $\begin{array}{l}76.7(21.6 \\
272.9)\end{array}$ & 0.956 \\
\hline PCT for Asia people & 3 & $90(84,94)$ & $91(84,96)$ & $9.57(5.21,17.55)$ & $0.10(0.04,0.23)$ & $\begin{array}{l}89.0(36.7 \\
215.9)\end{array}$ & 0.963 \\
\hline $\begin{array}{l}\text { PCT for non-Asia } \\
\text { people }\end{array}$ & 4 & $44(38,50)$ & $84(80,88)$ & $3.35(0.80,14.1)$ & $0.60(0.36,0.99)$ & $6.21(0.77,50.2)$ & 0.899 \\
\hline
\end{tabular}

Abbreviations: $P C T$ procalcitonin, $A A$ acute appendicitis, $C A$ complicated appendicitis

Beltran et al. [27] accessed high sensitivity for WBC counts and CRP levels (sensitivity, 0.9-1.0) to differentiate between patients with and without appendicitis, but low specificity (0.2-0.4) was observed. Gürleyik et al. [26] found that serum IL- 6 measurement is not of benefit in increasing the accuracy of the diagnosis of appendicitis with unacceptably high false-negative and -positive rates (16 and 54\%, respectively). Bilirubin was reported to have the highest sum of sensitivity (0.61) and specificity (0.61) with a threshold of $15 \mu \mathrm{mol} / \mathrm{L}$ by Kaser et al. [30]. However, there were insufficient evidence that proved the prior diagnostic accuracy and reliability than PCT. Of note, the overall sensitivity (0.62), specificity (0.86), and PLR (5.33) for PCT indicated a potential predictor for AA but not sufficient as a stand-alone measure to rule in or rule out AA, thus we suggest the possibility of utilizing PCT, clinical symptoms, and radiation (ultrasound, CT, and MRI) in an effort to increase the diagnostic accuracy in children with AA.

The present meta-analysis had some limitations. First, due to a focusing on pediatric patients, the included studies were limited in number. Also, some studies that reported both adults and children, but did not construct diagnostic data in children were excluded. Therefore, few studies with small sample sizes were included in this meta-analysis compared with adult analyses. Second, with no pre-existing widely accepted threshold, various diagnostic cut-off values were used in complicated AA; however, no heterogeneity form threshold effects were observed. Third, some of the included studies exhibited bias. Fourth, considering the cost of PCT detection, the benefit-to-cost ratio remains controversial. Therefore, our study was just hypothesis-generating. All findings need to be further investigated and confirmed in future studies.

\section{Conclusions}

In conclusion, our study suggests that PCT has potential diagnostic value in overall pediatric $\mathrm{AA}$ and has greater diagnostic value in identifying complicated pediatric AA. More studies are needed to further investigate and confirm the results.

\section{Abbreviations}

AA: Acute Appendicitis; AUC: Area Under the Curve; Cl: Confidence interval; DOR: Diagnostic odds ratios; FN: False negative; FP: False positive; PCT: Procalcitonin; ROC: Receiver operating characteristic; TN: True negative; TP: True positive

\section{Acknowledgements \\ Not applicable.}

\section{Authors' contributions}

WC and HL contributed to the study design, data collection, interpretation of data, and drafting the report; HN, XQ and LZ contributed to the data collection and statistical analysis and reviewed the report. All authors read and approved the final manuscript.

\section{Funding}

This study is funded by Key research and development project of Anhui Province, China (No.1704a0802172).

\section{Availability of data and materials}

All data generated or analyzed during this study are included in this published article.

\section{Ethics approval and consent to participate}

This study was exempted from obtaining informed consent by the Ethics Committee of Anhui Provincial Children's Hospital, Hefei, China with the ethical approval number of EYLL-2018-03.

\section{Consent for publication}

Not applicable.

\section{Competing interests}

The authors declare that they have no competing interests.

\section{Author details}

'Department of Scientific Research and Education, Anhui Provincial Children's Hospital, Wangjiang Road, Hefei 230051, Anhui, China. ${ }^{2}$ Anhui Institute of Pediatric Research, Hefei, Anhui, China. ${ }^{3}$ National Clinical Research Center for Kidney Disease; State Key Laboratory for Organ Failure Research; Renal Division, Nanfang Hospital, Southern Medical University, Guangzhou, China.

Received: 4 March 2019 Accepted: 3 July 2019

Published online: 09 July 2019

\section{References}

1. D'Souza N, Nugent K. Appendicitis. Am Fam Physician. 2016;93(2):142-3.

2. Vaziri M, Ehsanipour F, Pazouki A, Tamannaie Z, Taghavi R, Pishgahroudsari M, Jesmi F, Chaichian S. Evaluation of procalcitonin as a biomarker of diagnosis, severity and postoperative complications in adult patients with acute appendicitis. Med J Islam Repub Iran. 2014;28:50.

3. National Surgical Research C. Multicentre observational study of performance variation in provision and outcome of emergency appendicectomy. Br J Surg. 2013;100(9):1240-52. 
4. Acharya A, Markar SR, Ni M, Hanna GB. Biomarkers of acute appendicitis: systematic review and cost-benefit trade-off analysis. Surg Endosc. 2016;31(3):1022-31.

5. Gavela TCB, Serrano A. C-reactive protein and procalcitonin are predictors of the severity of acute appendicitis in children. Pediatr Emerg Care. 2012;28(5):416-9.

6. Rothrock SP, J: Acute appendicitis in children: emergency department diagnosis and management. Ann Emerg Med 2000;36(1):39-51.

7. D'Souza N, D'Souza C, Grant D, Royston E, Farouk M. The value of ultrasonography in the diagnosis of appendicitis. Int J Surg. 2015;13:165-9.

8. Aspelund G, Fingeret A, Gross E, Kessler D, Keung C, Thirumoorthi A, et al. Ultrasonography/MRI versus CT for diagnosing appendicitis. Pediatrics. 2014;133(4):586-93.

9. Whiting PFRA, Westwood ME, et al. QUADAS-2: a revised tool for the quality assessment of diagnostic accuracy studies. Ann Intern Med. 2011;155(8):529-36.

10. Bal AAM, Nartürk $M$, et al. Importance of clinical decision making by experienced pediatric surgeons when children are suspected of having acute appendicitis: the reality in a high-volume pediatric emergency department. Pediatr Emerg Care. 2017;33(9):e38-42.

11. Wang YJ, Lei HY, Zhang X. Application of serum CRP and PCT to diagnosis of infantile acute appendicitis. Med J Chin PAP. 2016;27(12):1218-20.

12. Yuchi JX, Liu C, Xu XQ. Efficacy of serum PCT levels in the prediction of acute Appendictis in children. J Clin Res. 2015;32(11):2125-7.

13. $\mathrm{Li} \mathrm{YH}, \mathrm{Xu} \mathrm{XN}$. The evaluation of procalcitonin in diagnosing acute appendicitis and mesenteric lymphadenitis in children. J Clin Pediatric Surg. 2015;14(2):124-41.

14. Kouame DB, Garrigue MA, Lardy H, Machet MC, Giraudeau B, Robert M. Is procalcitonin able to help in pediatric appendicitis diagnosis? Ann Chir. 2005;130(3):169-74.

15. Kafetzis DA, Velissariou IM, Nikolaides $P$, et al. Procalcitonin as a predictor of severe appendicitis in children. Eur J Clin Microbiol Infect Dis. 2005;24(7):484-7.

16. Chandel V, Batt SH, Bhat MY, Kawoosa NU, Yousuf A, Zargar BR. Procalcitonin as the biomarker of inflammation in diagnosis of appendicitis in pediatric patients and prevention of unnecessary appendectomies. Indian J Surg. 2011;73(2):136-41.

17. Benito J, Acedo Y, Medrano L, Barcena E, Garay RP, Arri EA. Usefulness of new and traditional serum biomarkers in children with suspected appendicitis. Am J Emerg Med. 2016;34(5):871-6.

18. Leli C, Ferranti M, Moretti A, Al Dhahab ZS, Cenci E, Mencacci A. Procalcitonin levels in gram-positive, gram-negative, and fungal bloodstream infections. Dis Markers. 2015;2015:701480.

19. Milcent K, Faesch S, Gras-Le Guen C, Dubos F, Poulalhon C, Badier I, et al. Use of Procalcitonin assays to predict serious bacterial infection in young febrile infants. JAMA Pediatr. 2016;170(1):62-9.

20. Memar MY, Varshochi M, Shokouhi B, et al. Procalcitonin: the marker of pediatric bacterial infection. Biomed Pharmacother. 2017;96:936-43.

21. Blab EKU, Tillawi S, et al. Advancements in the diagnosis of acute appendicitis in children and adolescents. Eur J Pediatr Surg. 2004;14(6):404-9.

22. de Kruif MD, Limper M, Gerritsen H, Spek CA, Brandjes DP, ten Cate $H$, et al. Additional value of procalcitonin for diagnosis of infection in patients with fever at the emergency department. Crit Care Med. 2010;38(2):457-63.

23. Yu CW, Juan LI, Wu MH; et al. Systematic review and meta-analysis of the diagnostic accuracy of procalcitonin, C-reactive protein and white blood cell count for suspected acute appendicitis. Br J Surg 2013;100(3):322-329.

24. Wu JY, Chen HC, Lee SH, Chan RC, Lee CC, Chang SS. Diagnostic role of procalcitonin in patients with suspected appendicitis. World J Surg. 2012;36(8):1744-9.

25. Abbas MH, Choudhry MN, Hamza N, et al. Admission levels of serum amyloid $\mathrm{a}$ and procalcitonin are more predictive of the diagnosis of acute appendicitis compared with C-reactive protein. Surg Laparosc Endosc Percutan Tech. 2014;24(6):488-94

26. Gürleyik GGE, Cetinkaya F. Serum interleukin-6 measurement in the diagnosis of acute appendicitis. ANZ J Surg. 2002;72(9):665-7.

27. Beltran MA, Almonacid J, Vicencio A, Gutierrez J, Cruces KS, Cumsille MA Predictive value of white blood cell count and C-reactive protein in children with appendicitis. J Pediatr Surg. 2007:42(7):1208-14.

28. Estrada JJ, Petrosyan M, Barnhart J, et al. Hyperbilirubinemia in appendicitis: a new predictor of perforation. J Gastrointest Surg. 2007;11(6):714-8.
29. Groselj-Grenc M, Repse S, Dolenc-Strazar Z, Hojker S, Derganc M. Interleukin6 and lipopolysaccharide-binding protein in acute appendicitis in children. Scand J Clin Lab Invest. 2007;67(2):197-206.

30. Kaser SA, Fankhauser G, Willi N, Maurer CA. C-reactive protein is superior to bilirubin for anticipation of perforation in acute appendicitis. Scand J Gastroenterol. 2010;45(7-8):885-92

31. Atahan KÜO, Aslan E, et al. Preoperative diagnostic role of hyperbilirubinaemia as a marker of appendix perforation. J Int Med Res. 2011;39(2):609-18.

32. Hong YR, Chung CW, Kim JW, Kwon Cl, Ahn DH, Kwon SW, et al. Hyperbilirubinemia is a significant indicator for the severity of acute appendicitis. J Korean Society Coloproctol. 2012;28(5):247-52.

33. Farooqui WPH, Burcharth J. The diagnostic value of a panel of serological markers in acute appendicitis. Scand J Surg. 2015;104(2):72-8.

\section{Publisher's Note}

Springer Nature remains neutral with regard to jurisdictional claims in published maps and institutional affiliations.
Ready to submit your research? Choose BMC and benefit from:

- fast, convenient online submission

- thorough peer review by experienced researchers in your field

- rapid publication on acceptance

- support for research data, including large and complex data types

- gold Open Access which fosters wider collaboration and increased citations

- maximum visibility for your research: over $100 \mathrm{M}$ website views per year

At $\mathrm{BMC}$, research is always in progress.

Learn more biomedcentral.com/submissions 